\title{
Aislamiento de especies de Cryptococcus asociadas con Eucalyptus en un parque de Bogotá
}

\author{
Alexandra Castañeda, Elizabeth Castañeda \\ Grupo de Microbiología, Instituto Nacional de Salud, Bogotá, D.C., Colombia.
}

\begin{abstract}
Con base en la información consignada en el herbario del Museo de Historia Natural de la Universidad Nacional sobre la presencia de un Eucalyptus camaldulensis en un parque de Bogotá, se diseñó este estudio con el fin de establecer si existía alguna asociación entre los eucaliptos presentes en el parque y las especies de Cryptococcus. Se recolectaron mensualmente durante 2 años, muestras de madera de 19 Eucalyptus. Estas se extrajeron con una solución tampón fosfato con antibióticos y el extracto se sembró en medios selectivos. De las 426 muestras obtenidas, se recuperaron 17 aislamientos de especies de Cryptococcus: 14 C. laurentii, 2 C. neoformans var. neoformans y 1 C. albidus. Se estableció la asociación del hongo con los eucaliptos; sin embargo, no se logró recuperar la variedad gattii.
\end{abstract}

Palabras clave: Cryptococcus neoformans, ecología, Eucalyptus.

\begin{abstract}
Isolation of Cryptococcus species from Eucalyptus trees located in a park in Bogotá
The presence in a northeast park of Bogota of a tree classified as Eucalyptus camaldulensis according to the registers of the National University herbarium prompted this study, aimed at establishing if there was an association of the Eucalyptus trees in this park with Cryptococcus spp. For 24 months, bark samples were monthly collected from 19 Eucalyptus trees. The samples were extracted with PBS buffer and cultured in a selective media. From 426 bark samples collected, 17 Cryptococcus isolates were recovered: $14 \mathrm{C}$. laurentii, $2 \mathrm{C}$. neoformans var. neoformans serotype $A$ and one $C$. albidus. The association between some Cryptococcus species and Eucalyptus trees was again established; nevertheless, C. neoformans var. gattii was not recovered.
\end{abstract}

Key words: Cryptococcus neoformans, ecology, Eucalyptus.

La criptococosis es una micosis sistémica causada por las dos variedades de la levadura Cryptococcus neoformans, que afecta tanto a individuos inmunocomprometidos como inmunocompetentes (1). La infección se adquiere por la inhalación de basidiosporas $(3 \mu \mathrm{m})$ o de blastoconidias poco encapsuladas $(4-5 \mu \mathrm{m})$, presentes en el medio ambiente (2). Estas pueden llegar al pulmón y diseminarse, por vía hematógena, al sistema nervioso central, donde causan meningitis, la forma clínica más frecuentemente diagnosticada de la entidad (1). Las dos variedades, var. neoformans y var. gattii,

\section{Correspondencia:}

acastaneda@hemagogus.ins.gov.co

Recibido: 23/11/00; aceptado: 21/12/00 presentan diferencias en su distribución geográfica, hábitat y características bioquímicas y genéticas (1-5).

El primer aislamiento ambiental de la var. neoformans fue reportado en 1894 a partir de jugo de duraznos (1); posteriormente, en 1951, Emmons logró recuperarla de suelos contaminados con excrementos de aves (5). Bajo estas condiciones, el hongo puede permanecer viable por varios años debido a que allí encuentra substratos favorables para su crecimiento, como son la creatinina y la urea $(3,6)$. También se la ha aislado de los detritos de algunos árboles como Eucalyptus, Cassia y Ficus $(7,8)$. Respecto al hábitat de la var. gattii, sólo hasta 1990 se logró el primer aislamiento a partir de Eucalyptus 
camaldulensis en Australia (9), estableciéndose así, por primera vez, la asociación de la variedad con una planta hospedera. Estos hallazgos fueron confirmados posteriormente en Estados Unidos (California), México, Italia e India (10-12). Adicionalmente, la var. gattii se ha encontrado asociada con otras especies de Eucalyptus como son E. tereticornis, E. gomphocephala y E. rudis (13-15), y en huecos de algunos árboles como oitíes (Moquilea thomentosa) y acacias (Cassia grandis) (8). Esporádicamente se ha informado la presencia de esta variedad en excrementos de murciélagos y en un avispero $(16,17)$. Es importante mencionar que todos los aislamientos ambientales de la var. gattii eran serotipo B; el primer aislamiento ambiental serotipo $\mathrm{C}$ se realizó en nuestro laboratorio, en 1997, a partir de detritos de almendros (Terminalia catappa) de Cúcuta, Norte de Santander, área endémica para la criptococosis por la var. gattii (18).

Con base en el informe de Ellis y Pfeiffer (9), en 1994 realizamos un estudio en el cual se estableció la asociación de diferentes especies de Cryptococcus (C. neoformans var. neoformans serotipo A, C. laurentii, $C$. albidus y $C$. uniguttulatus) con Eucalyptus ubicados en varias zonas de Bogotá (7). Sin embargo, en esa oportunidad no se logró recuperar la var. gattii.

En el Museo de Historia Natural del Instituto de Ciencias de la Universidad Nacional está consignada la ubicación de un E. camaldulensis en un parque ubicado en el noreste de Bogotá; la descripción fue realizada en 1979 por un australiano, G. Chippendale, quien de acuerdo con el registro del museo lo describió con un tamaño de 15 a 18 metros, corteza escamosa, ramas penduladas, botones florales verde claro y filamentos blancos con anteras, como se ilustra parcialmente en la figura 1. Basados en esta información, se planteó la realización de un estudio cuyo objetivo fue tratar de recuperar especies de Cryptococcus a partir de los Eucalyptus localizados en dicho parque.

Para tal fin, en el período de marzo de 1997 a marzo de 1999, se tomaron mensualmente cortezas de los troncos de los 19 Eucalyptus localizados en el parque, previo consentimiento

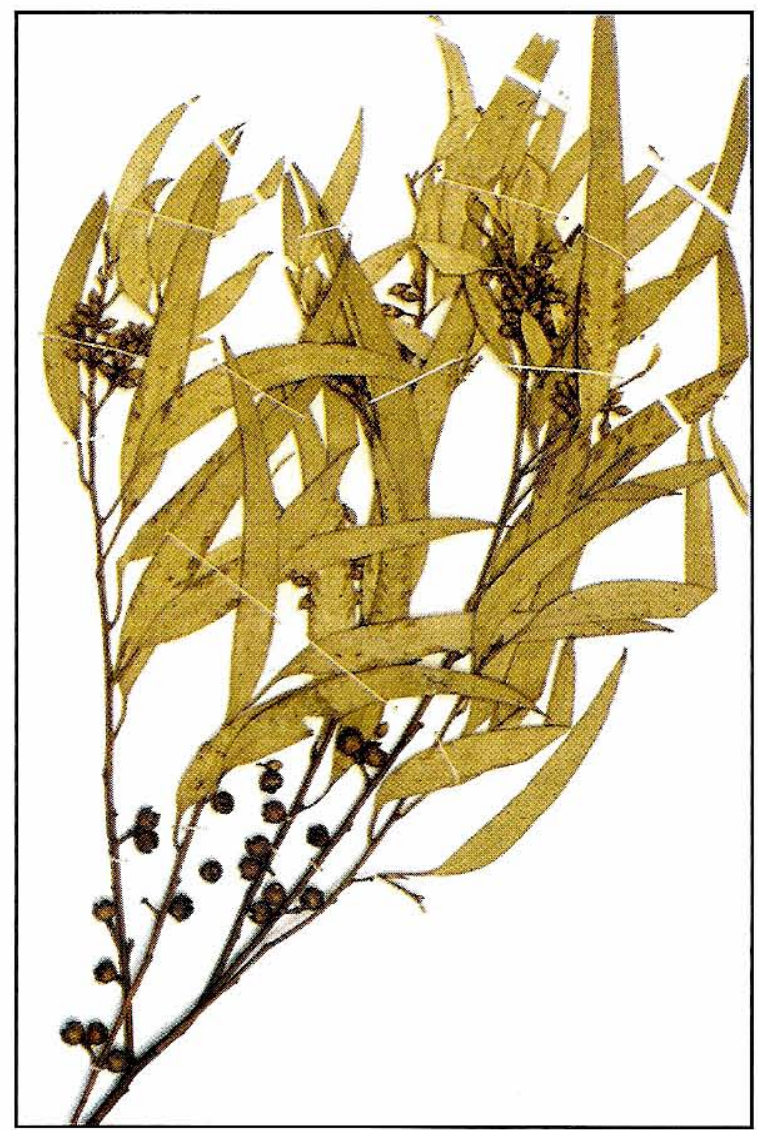

Figura 1. Eucalyptus camaldulensis: características de las hojas y frutos del árbol. Material del herbario del Museo de Historia Natural del Instituto de Ciencias de la Universidad Nacional de Colombia, Bogotá, D.C.

por escrito del Departamento Administrativo del Medio Ambiente de Bogotá. El procesamiento de las muestras se realizó raspando el interior de las cortezas hasta completar $5 \mathrm{~g}$ del material. A éste se le adicionaron $25 \mathrm{ml}$ de solución tampón fosfato; se mezcló en vórtex y se dejó en reposo durante 30 minutos; posteriormente, la suspensión se filtró a través de gasa estéril. Se adicionaron $50 \mu \mathrm{l}$ de una solución de antibióticos (penicilina $20 \mathrm{U}$ y estreptomicina $40 \mathrm{U}$ ) y se sembraron 100 $\mu \mathrm{l}$ de esta suspensión en agar-ácido cafeico y agar-semillas de Guizotia abyssinica (19). Las cajas se incubaron a $27^{\circ} \mathrm{C}$ durante un mes y se observaron periódicamente. Las colonias con cualquier tonalidad café, sugestivas del hongo (por la acción de la fenoloxidasa sobre el substrato), se resembraron en agar glucosado de Sabouraud 
Cuadro 1. Especies de Cryptococcus recuperadas durante el estudio, por año de aislamiento.

\begin{tabular}{lclr}
\hline Año & $\begin{array}{c}\text { Muestras } \\
\text { procesadas }\end{array}$ & $\begin{array}{c}\text { Especie de Cryptococcus } \\
\text { recuperadas }\end{array}$ & $\mathbf{n}$ \\
\hline 1997 & 190 & C. laurentii & 4 \\
& & C. albidus & 1 \\
1998 & 200 & C. laurentii & 10 \\
& & C. neoformans & 2 \\
1999 & 36 & var. neoformans, serotipo A & \\
Total & 426 & & 0 \\
\hline
\end{tabular}

para realizar las pruebas estandarizadas de confirmación como la determinación de actividades enzimáticas (fenoloxidasa, ureasa y nitratoreductasa), los patrones de asimilación de azúcares y la determinación de la variedad y del serotipo (19).

Durante el período de estudio, se recolectaron 426 muestras de madera, de las cuales 17 fueron positivas para levaduras del género Cryptococcus. La especie que se recuperó en mayor número fue $C$. laurentii, seguida por $C$. neoformans var. neoformans y $C$. albidus (cuadro 1). Es importante destacar que las colonias de $C$. laurentii y $C$. albidus presentaron algún tipo de pigmento en el medio selectivo, no obstante considerarse que estas especies no tienen actividad de fenoloxidasa (19).

De las tres especies aisladas de Cryptococcus, C. neoformans var. neoformans es patógena para humanos, especialmente en individuos inmunocomprometidos $(1,3)$. El hábitat de esta variedad se ha asociado desde 1950 con excrementos de palomas (5), aunque también se ha recuperado de huecos de acacias, ficus, mangos, cocos y de detritos de Eucalyptus $(3,7,8)$, sin que se haya demostrado aún una asociación directa entre el hongo y una planta en particular (3). La manera como el hongo podría adaptarse al hospedero vegetal sería a través de los productos de la biodegradación natural de la xilosa, celulosa y lignina, materiales presentes en la madera y que serían empleados como substrato para su desarrollo. Se ha asumido que esta degradación se podría realizar, en parte, por la enzima difenoloxidasa o lacasa, que posee la levadura y que se reconoce como un factor de virulencia $(3,13)$.
Si bien el estudio estaba enfocado a la búsqueda de $C$. neoformans var. gattii, por la estrecha asociación descrita entre esta variedad y $E$. camaldulensis, no fue posible recuperar esta variedad durante el tiempo del estudio a partir de los Eucalyptus ubicados en dicho parque.

Por otra parte, según el postulado de Ellis, para cada una de las variedades del hongo debería existir un animal intermediario y una planta hospedera, elementos que jugarian un papel muy importante en el ciclo de vida del hongo (2). Sin embargo, este postulado solamente se cumple en parte para cada una de las variedades; en la var. gattii serotipos B y $\mathrm{C}$, se ha establecido una asociación clara con algunas especies de Eucalyptus (E. camaldulensis, E. tereticornis) $(9,14)$ y con algunos árboles como oitíes y acacias $(8,16)$ así como con detritos de almendro (18). Con respecto al animal intermediario, existe una hipótesis en la que se involucra a los koalas (Phastolarctos cinereus), los cuales se alimentan principalmente de hojas de Eucalyptus y desarrollan una meningitis causada por esta variedad (20). En cuanto a la var. neoformans, durante muchos años se ha recuperado el hongo a partir de las excrementos de palomas $(1,5,6)$ y aunque ocasionalmente se le ha podido recuperar de árboles (8), todavía no se ha logrado establecer una asociación entre esta variedad y algún árbol en particular. En este estudio, el porcentaje de recuperación fue bajo (4\%), posiblemente debido, en parte, a que se tomaron únicamente muestras de madera. Para estudios posteriores sería importante incluir otro tipo de material como hojas, frutos, flores o detritos, en especial estos últimos porque a partir de ellos ha sido posible recuperar el hongo (7-14).

Sin embargo, es importante resaltar el aislamiento de C. neoformans var. neoformans a partir de los Eucalyptus estudiados, ya que este hallazgo contribuye con los datos existentes sobre la ecología de esta variedad y su asociación con material vegetal.

\section{Referencias}

1. Mitchell TG, Perfect JR. Criptococcosis in the era of AIDS-100 years after the discovery of Cryptococcus neoformans. Clin Microbiol Rev 1995;8:515-48. 
2. Ellis DH, Pfeiffer TJ. Ecology, life cycle, and infectious propagule of Cryptococcus neoformans. Lancet 1990;336:923-5.

3. Casadevall A, Perfect JR. Ecology of Cryptococcus neoformans. En: Cryptococcus neoformans. Washington, D.C.: ASM Press; 1998. p.351-80.

4. Boekhout $T$, Van Belkum A, Leenders AC, Verbreug $\mathrm{H}$, Mukamurangwa $\mathbf{P}$, Swinne $\mathbf{D}$, et al. Molecular typing of Cryptococcus neoformans: taxonomic and epidemiological aspects. Int J Syst Bacteriol $1997 ; 47: 432-42$

5. Emmons C. Isolation of Cryptococcus neoformans from soil. J Bacteriol 1951;62:685-90.

6. Littman ML, Borok R. Relation of the pigeon to cryptococcosis: natural carrier state, heat resistance and survival of Cryptococcus neoformans. Am J Epidemiol 1968;35:329-45.

7. Duarte A, Ordóñez N, Castañeda E. Asociación de levaduras del género Cryptococcus con especies de Eucalyptus en Santa Fe de Bogotá. Rev Inst Med Trop Sao Paulo 1994;35:125-30.

8. Lazera MS, Salmito MA, Londero AT, Trilles L, Nishikawa M, Wanke B. Possible primary ecological niche of Cryptococcus neoformans. Med Mycol 2000; 38:379-83.

9. Ellis D, Pfeiffer T. Natural habitat of Cryptococcus neoformans var. gattii. J Clin Microbiol 1990;28:16424.

10. Pfeiffer T, Ellis D. Environmental isolation of Cryptococcus neoformans var. gattii from California. J Infect Dis 1991;163:929-30.

11. Montagna MT, Viviani MA, Pulito A, Aralla C, Tortorano AM, Fiore L, et al. Cryptococcus neoformans var. gattii in Italy. Note II. Environmental investigation related to an autochthonous clinical case in Apulia. J Mycol Med 1997;7:93-6.

12. Chakrabarti A Jatana M, Kumar P, Chatha L, Kausahi A, Padhye A. Isolation of Cryptococcus neoformans var. gattii from Eucalyptus camaldulensis in India. J Clin Microbiol 1997;35:3340-2.

13. Cabral LF. Wood, animals and human beings as reservoirs for human Cryptococcus neoformans infection. Rev Iberoam Micol 1999;16:77-81.

14. Pfeiffer TJ, Ellis DH. Environmental isolation of Cryptococcus neoformans var. gattii from Eucalyptus tereticornis. J Med Vet Mycol 1992;30:407-8.

15. Swinne D, Bauwens L, Desmet P. More information about the natural habitat of Cryptococcus neoformans. ISHAM Mycoses Newsletter 1992;60:4

16. Lazera M, Wanke B, Nishikawa M. Isolation of both varieties of Cryptococcus neoformans from saprophytic sources in the city of Rio de Janeiro, Brazil. J Med Vet Mycol 1993;31:449-54.

17. Gezuele E, Cale L. Isolation in Uruguay of Cryptococcus neoformans var. gattii from a Polybia occidentalis. Rev Iberoam Micol 1993;10:5-6.

18. Callejas A, Ordóñez N, Rodríguez MC, Castañeda E. First isolation of Cryptococcus neoformans var. gattii, serotype $C$, from the environment in Colombia. Med Mycol 1998;36:341-4

19. Warren NG, Hazen KC. Candida, Cryptococcus, and other yeast of medical importance. En: Murray PR, Baron EJ, Pfaller MA, Tenover FC, Yolken RH, editores. Manual of Clinical Microbiology. $7^{\text {th }}$ ed. Washington, D.C.: ASM Press 1999;1184-99.

20. Bolliger A, Finckh ES. The prevalence of cryptococcosis in the koala (Phastolarctos cinereus) Med J Aus 1992;49:545-7. 